\title{
Discussion: Renewables and the grid: understanding
} intermittency

\section{R. Gross, P. Heptonstall, M. Leach, D. Anderson, T. Green and J. Skea}

Michael Laughton, Emeritus Professor, University of London

There is a certain small 'whistling in the wind', or lack of it, in this paper, in asserting that over wide geographic areas such as Germany or Denmark, and by implication the UK, extreme fluctuations are only 20-30\% of installed capacity. This may well be for short term variations happening in a few hours, but for capacity planning purposes the larger variations that occur over longer periods in the output of the total installed wind capacity have to be considered.

Recent simulated power generation results (Renewable Energy Foundation, 2006) for $25 \mathrm{GW}$ of wind generation across the UK have been based on renewable output certificate (ROC) data from the office of the electricity industry regulator, Ofgem, and correlated with historic wind data from the Met Office. The results indicate that over the period of 1995 to 2006, for example, wind power in January on average would have varied by $94 \%$ of installed capacity, with power swings of 70\% of capacity over $30 \mathrm{~h}$ being commonplace. The average minimum wind power output for these months would have been only 3.7\% of capacity, maximum changes of output of 99\% of capacity (in 1998 and 1999), minimum outputs of $0.6 \%$ (in 1999) and 1\% of capacity (in 2006). In such circumstances the wind capacity credit is practically zero.

For the UK's essentially island electricity supply system, the capacity credit from many studies and based on probabilities (LOLP) of 9\% appears to be about the square root of the wind capacity installed when measured in GW, that is $25 \mathrm{GW}$ of wind plant has a capacity credit of about $5 \mathrm{GW}$. This rule is used also in the national grid 2007 seven year statement. For levels of either zero or LOLP-supported levels of capacity credit, however, the UKERC paper shows that the incremental reliability costs are small, a valuable result.

The limited capacity credit is of particular significance, on the other hand, in planning studies. The authors quote the national grid's current (2006) indicative level of adequate system margin of around 20\% above peak demand, or 12-14 GW. Using the square root of GW of wind capacity installed, analyses show that such levels of capacity credit will never be more than this planning margin. This means that the total conventional plant capacity required in the system will never be less than the peak load irrespective of the amount of added wind capacity. A further unforeseen and unlooked for consequence of this somewhat surprising result is that if nuclear is not replaced with nuclear, it will have to be replaced with conventional fossil fuel stations.

The immediate conclusion is that until new solutions emerge that will add substantially to the overall capacity credit of a more varied combination of variable energy sources, much otherwise uneconomic conventional plant will need to be retained or replaced, either running on low or minimum output, or be replaced by plant capable of frequent rapid start and ramping of output, such as (aero-derivative) open cycle gas turbine (OCGT) generators.

These outcomes place especially onerous reliability-linked security of supply requirements on market-driven investment and are perhaps not widely appreciated. They also represent a challenge to devising new methods for reducing the impact of the variability of renewable sources connected to the grid. 